\title{
CONSELHO DE COMUNICAÇÃO SOCIAL Uma válvula para o diálogo ou para o silêncio?
}

\section{Anita Simis}

\section{Introdução}

Nos anos de 1990, com as pressões pela desregulamentação da comunicação e das telecomunicaçōes, o papel do Estado neste âmbito foi reduzido e muitas vezes direcionado apenas a regulamentar partes, nem sempre as mais significativas, principalmente no campo da televisão. Diversos países europeus, onde a televisão era essencialmente pública, sentiram essa transformação, inicialmente com a introdução da televisão por assinatura, mas depois também na própria televisão aberta a partir da entrada de canais privados. No entanto, onde houve encolhimento do Estado, fortaleceu-se a participação da sociedade civil por meio de conselhos de comunicação que, inclusive, tendo em vista o papel proeminente dos meios de comunicação em

Artigo recebido em janeiro/2009

Aprovado em agosto/2009 diversos âmbitos, tornaram o desempenho efetivo de um conselho dialogando com a sociedade uma medida que vem aprimorando as formas de atuação democrática.

No Brasil, por sua vez, onde tínhamos um Ministério das Comunicaçōes robusto, atuante e conforme as diretrizes autoritárias dos governos militares, a instituição de um Conselho sinalizava uma participação menos vinculada a interesses privados e mais plural. Mas, embora a implantação do Conselho de Comunicação Social estivesse prevista já na Constituição de 1988 (art. 224), o mesmo só foi instituído em 2002. No intervalo, durante a década de 1990, a liberdade de expressão se confundiu com a busca de audiência a qualquer custo pelas emissoras de TV e assistimos a programaçôes de péssima qualidade. Nesse contexto, os esforços no sentido de ativar o Conselho partiram de entidades da sociedade civil, representadas no Fórum Nacional pela Democratiza- 
ção da Comunicação, ${ }^{1}$ que se mobilizaram em prol da criação da lei que o regulamentou (lei 8.389, de 30/12/91), e pela atuação incansável de parlamentares como a deputada Irma Passoni (PT-SP) e Luiza Erundina (PSB-SP). Posteriormente, mesmo a lei que o regulamentou reafirmando a sua implantação, pois ele deveria ser eleito em até sessenta dias após a publicação da referida lei e instalado em até um mês após a sua eleição, só teve êxito dez anos depois.

Este artigo procura justamente analisar a trajetória do Conselho de Comunicação Social - CCS -, sua importância, e explicar por que o Conselho, ainda que apenas como órgão auxiliar do Congresso Nacional nas questôes relativas aos meios de comunicação, previsto desde a promulgação da Constituição Federal, regulamentado em 1991, só foi efetivamente implantado catorze anos depois, precisamente em 5 de junho de 2002, com a indicação de todos seus treze representantes. A partir de então, o Conselho funcionou normalmente, e vencidos os mandatos de seus primeiros membros, em fevereiro de 2005, foram confirmados os membros para o novo período de dois anos. No final de 2006, no entanto, o CCS fez sua última reunião e os membros para um terceiro mandato não foram indicados. Desde então o CCS nunca mais se reuniu. Mas, o que levou o Conselho a deixar de existir não foi apenas uma questão burocrática. Em outras palavras, o que leva à presidência do Senado Federal, responsável pela nomeação dos representantes dos diversos segmentos da sociedade que têm assento no conselho, a não encaminhar os nomes dos novos membros é uma questão política.

\section{Prólogo}

A importância atribuída ao funcionamento de tal Conselho foi apontada em vários níveis. Já em 1995, no plano mais geral, nas palavras do Fórum, viabilizaria

[...] o primeiro espaço institucional especializado no debate das questôes da área das comunicações, rompendo o circuito restrito aos bastidores do Executivo e acessível apenas ao empresariado de comunicação e alguns parlamentares. Sem o Conselho, teremos o agravamento do caos jurídico na área das comunicaçōes e uma situação inevitável de confronto (Boletim, 1995, p. 3).

$\mathrm{Na}$ época, esse caos não chegou a se verificar, como veremos mais adiante, ainda que seja cada vez mais criticada a ausência de um controle sobre conteúdo dos meios de comunicação, meios percebidos como agentes de novas formas de socialização e com grande influência sobre os indivíduos, mas que deixam a desejar na construção da democracia e da cidadania.

No plano mais específico, o valor do Conselho residia em viabilizar diversas formas de regulamentar as relações da produção independente, inclusive do cinema, com a televisão. De fato, se já na Constituição estava previsto que a produção e a programação das emissoras de televisão promoveriam a cultura nacional e regional e estimulariam a produção independente que tivesse como objetivo sua divulgação (art. 221), na lei 8.389/91, art. $2^{\circ}$, que institui o Conselho, temos:

O Conselho de Comunicação Social terá como atribuição a realização de estudos, pareceres, recomendaçôes e outras solicitações que lhe forem encaminhadas pelo Congresso Nacional [...] em especial sobre:

a) liberdade de manifestação do pensamento, da criação, da expressão e da informação;

[...]

d) produção e programação das emissoras de rádio e televisão;

e) monopólio ou oligopólio dos meios de comunicação social;

f) finalidades educativas, artísticas, culturais e informativas da programação das emissoras de rádio e televisão;

g) promoção da cultura nacional e regional, e estímulo à produção independente e à regionalização da produção cultural, artística e jornalística;

h) complementaridade dos sistemas privado, público e estatal de radiodifusão2;

[...] 
j) propriedade de empresa jornalística e de radiodifusão sonora e de sons e imagens;

l) outorga e renovação de concessão, permissão e autorização de serviços de radiodifusão sonora e de sons e imagens;

m) legislação complementar quanto aos dispositivos constitucionais que se referem à comunicação social. [...].

Ainda que a lei não previsse o Conselho como um órgão deliberativo e independente, como inicialmente proposto, pretendia-se romper com o fechado circuito de tomada de decisões que prevalecia sobre esta área há algumas décadas, sobretudo a partir do Regime Militar, que confinava os assuntos aos bastidores do Ministério das Comunicaçōes com acesso exclusivo do empresariado de comunicação. Estas influências patrimonialistas ainda prevaleciam após encerrados os trabalhos da Assembléia Nacional Constituinte e podem ser exemplificadas com a forma como se regulamentou a televisão a cabo, disfarçada com a denominação de Distribuição de Sinais de Televisão (DISTV), por meio da Portaria 250/89. Tratava-se de uma medida que, juntamente com um decreto anterior, 95744/88, que regulamentava o Serviço Especial de Televisão por Assinatura (TVA), formulava as bases iniciais da política para o mercado da televisão por assinatura e que foi complementada com a Portaria 43/94 que implantava o sistema MMDS (transmissão por microondas), na ocasiāo denominado de Canais para os Sistemas de Circuito Fechado de Televisão com Utilização de Radioenlace (CFTV). Como afirma Ramos:

Assim, nesse emaranhado de siglas retiradas de obscuras portarias e decretos gestados na intimidade da relação privada entre políticos com interesses diretos no negócio, empresários associados direta ou indiretamente a esses interesses e a tecnoburocracia ministerial, estava a base técnico-normativa para profundas alteraçōes estruturais na economia-política dos meios de comunicação de massa no Brasil. Siglas novas dando ares de modernidade aos velhos modos oligárquicos de se fazer política nas comunicaçōes brasileiras (2000, p. 149).
É interessante notar que, ao menos neste processo, o Estado não se apresentou como um ator à frente dos empresários, dando um tratamento estratégico à implantação da televisão por assinatura. Se houve tentativas no sentido de implantá-la durante toda década de 1970, foi apenas nos anos de 1990 que ela se efetivou, e só agora com uma visão estratégica, por meio da lei 8.977/95, conhecida como Lei de TV a Cabo. ${ }^{3}$ Em outras palavras, ao integrar a televisão a cabo ao Sistema Nacional de Telecomunicações, consolidando o conceito fundamental de rede única e pública, deixou-se de considerá-la apenas como um serviço especial de telecomunicaçōes não aberto à correspondência pública, um sucedâneo menor da radiodifusão, subestimando seu potencial social e seu papel no desenvolvimento das telecomunicações como um todo. Agora, ao contrário da caracterização do serviço como especial, restrito porque codificado e, portanto, diverso da televisão convencional, que é recebida direta e livremente pelo público, o que se propunha eram redes únicas capazes de formar uma imensa teia de comunicações, pois todas as redes físicas deveriam ter a mesma conectividade e ser públicas, no sentido de que as pessoas jurídicas privadas que viessem a explorar o transporte de sinais não pudessem discriminar o acesso de ninguém às suas redes. Por outro lado, não se tratando de propriedade estatal, a participação da sociedade estaria dada na forma de um Conselho, o Conselho de Comunicação Social (cf. Ramos, 2000, pp. 155-159). Por ter sua instalação seguidamente protelada por parte da mesa do Senado, os representantes do Fórum pressionaram pela inclusão de um artigo especificando mais as atribuições do Conselho, exigindo que a regulamentação da lei fosse por ele apreciada "para não passar um cheque em branco para o Executivo" (Boletim, 1995, p. 4). Assim conforme o artigo $4^{\circ}$, da lei 8.977/95, conhecida como Lei da TV a cabo, temos:

O Serviço de TV a Cabo será norteado por uma política que desenvolva o potencial de integração ao Sistema Nacional de Telecomunicações, valorizando a participação do Poder Executivo, do setor privado e da sociedade, em regime de cooperação e complementariedade, nos termos desta lei. 
$\$ 1^{\circ}$ A formulação da política prevista no caput deste artigo e o desenvolvimento do Serviço de TV a Cabo serão orientados pelas noções de Rede Única, Rede Pública, participação da sociedade, operação privada e coexistência entre as redes privadas e das concessionárias de telecomunicações.

$\$ 2^{\circ}$ As normas e regulamentações, cuja elaboração é atribuída por esta lei ao Poder Executivo, só serão baixadas após serem ouvidos os respectivos pareceres do Conselho de Comunicação Social, que deverá pronunciar-se no prazo de trinta dias, após o recebimento da consulta, sob pena de decurso de prazo. (grifo meu $)^{4}$

Esta nova situação resultou do trabalho que um grupo de entidades sindicais e setores acadêmicos, afora alguns parlamentares, vinham desenvolvendo desde meados da década de 1970 no sentido de democratizar a comunicação no país, especialmente no que dizia respeito à televisão por assinatura, e que contribuiu para a constituição da Frente Nacional de Luta pela Democratização da Comunicação, no início dos anos de 1980, depois transformada no Fórum Nacional pela Democratização da Comunicação, já mencionado como principal articulador da lei que regulamentou o Conselho.

Para entendermos melhor o avanço que essas articulações produziram, retornemos às origens da discussão sobre o Conselho. Conforme Othon Jambeiro, durante a Assembléia Constituinte, a proposta de um Conselho polarizou o debate em dois grandes grupos: de um lado, a Federação Nacional dos Jornalistas (Fenaj), que diante de divergências com os outros membros da Frente e da urgência de um interlocutor se impôs como representante das chamadas forças da sociedade civil organizada, aliada à base progressista dos parlamentares; de outro lado, a Associação Brasileira das Emissoras de Rádio e Televisão (Abert), ligada aos parlamentares do chamado "centrão": "a Abert defendia que a radiodifusão deveria ser controlada pelo poder Executivo e explorada pela iniciativa privada", "nos moldes estabelecidos pela legislação então em vigor", e a Fenaj "a criação de um Conselho Nacional de Comunicação [...] um órgão coletivo autônomo, com atribuições executivas, e composto, na sua maioria, por representantes de entidades de trabalhadores e da sociedade civil. A exploração dos serviços de rádio e TV deveria ser feita por fundaçôes sem fins lucrativos" (Jambeiro, 2000, pp. 82-83, e 2001, p.146). ${ }^{5}$ Depois de longas negociaçôes, a Constituição, como já afirmamos, além de determinar "que a exploração dos serviços de TV deve ser feita por entidades privadas, públicas e estatais" de forma complementar, estabeleceu que o Conselho seria apenas um órgão consultivo do Congresso, agora chamado de Conselho de Comunicação Social, fixando ainda que as concessões seriam deslocadas do eixo do Poder Executivo para o Legislativo, pois deveriam ser aprovadas agora também pelo Congresso (Jambeiro, 2000, p. 83). ${ }^{6}$ Tornar o Conselho apenas consultivo foi a saída para sua criação e mesmo assim contrariando as pretensões da Abert.

Desse modo, fruto de negociação, ao próprio Conselho caberia estender a busca pela resolução de conflitos e gerar bases de consenso, sem que as posiçōes em disputa abdicassem dos seus princípios ou da condição de parte. Para tanto, conforme a lei 8.389/91, a composição do Conselho de Comunicação Social compreenderia treze representantes de vários setores:

1. Um das empresas de rádio;

2. um das empresas de televisão;

3. um das empresas de imprensa escrita;

4. um engenheiro com notórios conhecimentos na área de comunicação social;

5. um da categoria profissional dos jornalistas;

6. um da categoria profissional dos radialistas;

7. um da categoria profissional dos artistas;

8. um das categorias profissionais de cinema e vídeo;

9. cinco membros representantes da sociedade civil.

No entanto, embora o Conselho devesse ser um órgão de interlocução da sociedade com o Congresso e com o Executivo, é de se notar que esta composição, diferentemente de outros Conselhos, não contempla membros representantes seja do Poder Executivo, seja do Poder Legislativo. De fato, a 
tradição brasileira mostra que na composição dos Conselhos ao menos o Poder Executivo sempre se faz presente, não só para implementar as políticas, quando o Conselho tem não apenas a função de assessorar o Poder Executivo ou formular diretrizes, como também de fiscalizar o cumprimento da legislação. Assim, podemos exemplificar citando o Conselho Nacional dos Direitos da Criança e do Adolescente (Conanda), que é integrado por representantes do Poder Executivo, assegurada a participação dos órgãos executores das políticas sociais básicas na área de ação social, justiça, educação, saúde, economia, trabalho e previdência social e, em igual número, por representantes de entidades não-governamentais de âmbito nacional de atendimento dos direitos da criança e do adolescente. $\mathrm{Ou}$ tro exemplo: o Conselho Nacional dos Direitos da Mulher, que foi vinculado ao Ministério da Justiça e, no atual governo, passou a integrar a estrutura da Secretaria Especial de Políticas para Mulheres da Presidência da República, contando em sua composição com representantes da sociedade civil e do governo. Mas talvez o Conselho Nacional de Política Cultural (CNPC) seja o melhor exemplo, pois é um órgão mais próximo das questôes relativas à comunicação. Ele funciona com 46 titulares escolhidos entre personalidades eminentes da cultura brasileira e de reconhecida idoneidade, além de representantes do Poder Público Federal, do Poder Público dos Estados e dos Municípios, entre outros, e ainda, sendo órgão colegiado integrante da estrutura básica do Ministério da Cultura, é presidido por seu ministro. Mesmo o Conselho Federal de Cabodifusão, que constava do projeto de lei, apresentado ao Congresso Nacional em 30 de outubro de 1991 pelo deputado Tilden Santiago (PT-MG), portanto o antecessor do projeto que instituiu o Conselho de Comunicação Social, conforme Ramos, previa uma composição que contava com representantes do Congresso Nacional. ${ }^{7}$

Esta forma sui generis não passou desapercebida aos membros do Fórum:

Observe-se que, no caso dos pareceres aos regulamentos e normas, o Ministério das Comunicações não ouvirá o Congresso, mas sim o Conselho, isto é, os setores da sociedade repre- sentados no Conselho. Este, por sua vez, não impōe uma subordinação indevida entre o Executivo e o Congresso, pois o enlace é político e não administrativo. $\mathrm{O}$ que foi criado é uma nova modalidade de relaçãao entre o Estado e a sociedade, sem dúvida, estranha à tradição republicana (Boletim, 1995, p. 5)

Inicialmente pretendia-se, inclusive, que o Conselho atuasse como instância autônoma em relação ao Executivo e ao Legislativo, mas por pressão do empresariado de comunicação, durante os trabalhos da Constituinte, acabou-se por inseri-lo no interior do Congresso (Idem, p. 4) e mesmo assim adiou-se sua existência por mais alguns anos.

De início a não instalação do Conselho foi atribuída mais a uma manobra por parte do Executivo, de segmentos do empresariado e de parlamentares no sentido de adiar a regulamentação da Lei da TV a Cabo, uma vez que o decreto presidencial só poderia ser baixado após serem emitidos os pareceres do Conselho de Comunicação Social (lei 8.977, de $6 / 1 / 95$, art. $4^{\circ}$, pgr. $2^{\circ}$ e art. $44^{\circ}$, já citado). Assim, embora a Lei de TV a Cabo estipulasse que os regulamentos e as normas necessários para implementar suas disposições deveriam ser baixados até junho de 1995, sem a sua regulamentação não poderiam ser feitas novas concessóes e, portanto, não haveria novos competidores, o que beneficiaria os operadores já atuantes. Por outro lado, sem esta regulamentação, os canais de utilidade pública e de acesso público, como o canal da Câmara, do Senado, o comunitário etc., não poderiam ser implantados e não seriam propostas medidas no sentido de estipular como as televisões a cabo deveriam participar no estímulo e incentivo do desenvolvimento da indústria cinematográfica nacional.

Para contornar o impasse, principalmente porque o mercado de televisão a cabo já vinha funcionando de forma precária em todo o país, o governo em vez de instituir a regulamentação da lei por decreto, inicialmente remeteu uma proposta para a Câmara (cf. O Estado de S. Paulo, 1995). No entanto, em 28 de novembro de 1995 foi baixado o decreto 1.718, aprovando o regulamento do serviço de televisão a cabo, após ter sido objeto de duas consultas públicas promovidas pelo Ministé- 
rio das Comunicações e incorporado as sugestões recebidas. No mesmo dia, pelo decreto 1.719 , é promulgado o regulamento de outorga de concessão ou permissão para exploração de serviços de telecomunicações em base comercial. Em 4 de dezembro, o decreto 1.719 foi revogado e, em 14 de abril de 1997, outro decreto, n. 2.206, revogou o decreto 1.718 e atualmente é ele que deve ser observado quanto ao regulamento do serviço de televisão a cabo.

Nesse sentido, se houve uma manobra tática para impedir o Conselho de se instalar e assim impedir a entrada de novos concorrentes, verifica-se que ela foi bem-sucedida durante alguns meses. Dito de outro modo, a regulamentação existe desde 1997 e o Conselho só foi efetivamente instalado, e passou a se reunir, a partir de 2002. E o que é mais significativo: uma análise superficial desta regulamentação mostra que mesmo sem a atuação do Conselho, algumas medidas foram implementadas, inclusive atendendo a antigas reivindicaçôes de setores articulados no Fórum e exteriores a ele. O melhor exemplo talvez seja o artigo 67 , do decreto $1.718 / 95$, reafirmado no artigo 74 , do decreto $2.206 / 97$, que obrigou as operadoras de televisão a cabo a oferecerem ao menos um canal exclusivo para a exibição da produção cinematográfica nacional, disponibilizado em bases comerciais. Esta foi a brecha aberta para que alguns cineastas se empenhassem em levar ao ar o Canal Brasil, no qual, em associação com a Globosat, o grupo entra com uma quantidade mínima de filmes para permitir o funcionamento do canal e a Globosat entra com os meios.

Talvez uma explicação mais consistente tenha sido a resistência por parte do Poder Legislativo em viabilizar o Conselho. De fato havia uma divergência quanto às entidades que formariam o CCS e o presidente do Congresso, senador José Sarney, provavelmente pressionado por parte de parlamentares detentores de concessões de rádio e TV. O Ministério enviou ao Senado o decreto 1.718 e pretendia fazer o mesmo com as normas complementares, alegando que estava cumprindo o que determina a lei 8.977/95 e que, se o Conselho ainda não havia sido instituído, pelo fato de ser um órgão consultivo do Senado, caberia àquela Casa receber os atos referentes à TV a cabo (cf. Nogueira, 1996).
Complementando essa explicação, é provável que a "falta de interesse" do presidente do Senado em conferir atribuições ao Conselho tenha resultado da disputa de poderes com o trabalho desenvolvido pelas Comissões Técnicas do Congresso: Comissão de Educação, no Senado, e Comissão de Ciência, Tecnologia, Comunicação e Informática da Câmara dos Deputados. Sem dúvida, este dado é significativo na medida em que, como já foi apontado, a composição do Conselho não somava com a representação seja da Câmara dos Deputados, seja do Senado.

É preciso recordar que ao menos a Comissão de Ciência, Tecnologia, Comunicação e Informática da Câmara dos Deputados, quando foi presidida pela deputada Irma Passoni no período de 1992 a 1993, criou, nas palavras de Ramos (2000, pp. 153-154), um "grupo informal de assessoramento", incluindo desde o Fórum até as Organizações Globo, desde a Universidade de Brasília até a Associação Brasileira de Emissoras de Rádio e Televisão e que posteriormente foi alargado por dois grupos: um fabricante de fibras óticas e outro do Sistema Telebrás, além de representantes do Ministério das Comunicações. Em outras palavras, o "grupo" exerceu o papel que caberia ao Conselho e não por acaso esta ação pode ser considerada o embrião de um complexo processo na busca do consenso que resultou na aprovação da Lei de TV a Cabo.

Há ainda outros pontos a serem levados em consideração e questionados. Criticou-se a forma corporativa que acabou por compor o Conselho de Comunicação Social. No entanto, a maior parte das entidades e seus representantes indicados para compor o Conselho atuaram na Lei de TV a Cabo que é apresentada como o resultado de um inédito e transparente processo de negociação, cujo substitutivo, do deputado Koyu Iha (PSDB-SP), foi acolhido integralmente pela Câmara e Senado. ${ }^{8}$ Isso sem contar que na composição estão cinco representantes da sociedade civil.

Além da definição de critérios para a indicação dos representantes, alguns dos entraves que ocorreram durante o período de 1992 a 2002 foram a ausência de entidades representativas de caráter nacional de algumas categorias profissionais ou mesmo a existência de mais de uma entidade representativa 
de dois desses segmentos, no caso o da imprensa escrita e o da TV, e a regulamentação de um sistema de eleição pelo Congresso Nacional (em cada casa separadamente ou nas duas conjuntamente).

Mas, certamente mais problemático tenha sido a indicação dos cinco "representantes da sociedade civil", inclusive porque entre estes, conforme estipula a legislação, são indicados o presidente e vicepresidente do Conselho. Os outros membros a serem eleitos - três empresários, quatro profissionais na área da comunicação e um engenheiro - certamente não trouxeram maiores conflitos para serem escolhidos por suas respectivas áreas, embora, como já apontamos, alguns tenham por vezes mais de uma entidade para cada categoria. Mas, como escolher entidades para os cinco representantes da sociedade civil? Quais poderiam ser os critérios? Entidades como a Conferência Nacional dos Bispos do Brasil e a Ordem dos Advogados do Brasil chegaram a ser consultadas, mas acabaram não figurando na listagem eleita. E por que não incluir outros membros à composição do Conselho, como as universidades ou, conforme chegou a propor o deputado Cunha Bueno (Projeto de Lei 232/93), as empresas de propaganda e os profissionais dessa área? E mais, quem assumiria o papel de árbitro nas disputas envolvidas, cuja polaridade apontada é entre "entre os que se beneficiaram de décadas de procedimentos antidemocráticos na área das comunicações e os que querem abrir este processo para a sociedade"??

O que sabemos é que em 2002 foi feito um acordo entre os líderes do Senado, a partir de reivindicaçôes surgidas principalmente do Fórum Nacional pela Democratização da Comunicação e da negociação sobre a proposta de emenda constitucional (PEC 5/2002), que permitia ao capital estrangeiro a participação em $30 \%$ do controle acionário das empresas de jornalismo e de radiodifusão, mudando o artigo 222 da Constituição Federal, que restringia a propriedade das empresas de comunicação a brasileiros natos ou naturalizados há mais de dez anos e permitia que pessoas jurídicas nacionais pudessem participar de $100 \%$ das empresas. ${ }^{10}$ Ora, com a entrada do capital estrangeiro nas empresas de comunicação, a importância do Conselho redobrava, pois caberia a ele fiscalizar essa entrada de capital. Ainda assim a indicação de um nome ligado à Rede Record na vaga das empresas de TV desagradou à Globo e ao SBT, e o PT discordou da indicação de três funcionários da Câmara e do Senado para as vagas destinadas a representantes $\mathrm{da}$ sociedade civil.

Finalmente, em maio de 2002 foi formalizada uma chapa indicada por líderes partidários e as seguintes entidades: Fórum Nacional pela Democratização da Comunicação (FNDC); Associações Brasileiras de Empresas de Rádio e Televisão (Abert), de Radiodifusão Comunitária (Abraço), de Radiodifusão e Telecomunicações (Abratel), de Televisão por Assinatura (ABTA), de Imprensa (ABI) e de Emissoras Públicas, Educativas e Culturais (Abepec); Associaçôes Nacionais de Editoras de Revistas (Aner), de Jornais (ANJ) e de Entidades de Artistas e Técnicos em Espetáculos de Diversōes (Aneate); Congresso Brasileiro de Cinema (CBC); Conselho Federal de Psicologia (CFP); Executiva Nacional de Estudantes de Comunicação (Enecos); Federação Interestadual dos Radialistas (Fitert); a Federação Nacional dos Jornalistas (Fenaj); Agência de Notícias dos Direitos da Infância (Andi); União Independente de Emissoras de TV (UniTV); Rede Brasil de Comunicação Cidadã (RBC); Instituto Brasileiro de Comunicação Cristã (Inbrac); Sindicatos Nacionais de Cinema e Vídeo (STIC/Sindcine) e Sociedade Brasileira de Engenharia de Televisão e Telecomunicações (SET). Foram então indicados os representantes indicados na Tabela 1.

No dia 5 de junho de 2002, em sessão do Congresso Nacional, a Presidência do Senado estabeleceu normas regulamentando a eleição do Conselho de Comunicação Social e senadores e deputados foram convidados a votar "sim" ou "não" em relação à cédula única com a chapa completa dos candidatos a titulares e suplentes do Conselho, que seriam considerados eleitos caso obtivessem a maioria dos votos. A eleição processou-se com sucesso, obtendo-se o seguinte resultado: na Câmara dos Deputados, votaram 286 deputados, sendo 217 votos "sim", 13 votos "não", 54 votos em branco e 2 votos nulos. No Senado Federal, votaram 58 senadores, sendo 49 votos "sim", 4 votos "não", 5 votos em branco e nenhum voto nulo. 
Tabela 1

\begin{tabular}{|c|c|c|c|}
\hline Lei $n^{\circ} 8.389 / 91$, art. $4^{\circ}$ & Titulares & Suplentes & $\begin{array}{l}\text { Entidades que indicam } \\
\text { titular/suplente }\end{array}$ \\
\hline $\begin{array}{l}\text { Representante das empresas } \\
\text { de rádio (inciso I) }\end{array}$ & $\begin{array}{l}\text { Paulo Machado de } \\
\text { Carvalho Neto }\end{array}$ & Emanuel Soares Carneiro & $\begin{array}{l}\text { Abert/Entidades Estaduais } \\
\text { de Rádio e TV/Rádio } \\
\text { Itatiaia }\end{array}$ \\
\hline $\begin{array}{l}\text { Representante das empresas } \\
\text { de televisão (inciso II) }\end{array}$ & Roberto Wagner Monteiro & Flávio de Castro Martinez & Abratel \\
\hline $\begin{array}{l}\text { Representante de empresas } \\
\text { da imprensa escrita } \\
\text { (inciso III) }\end{array}$ & Paulo Cabral de Araújo & Carlos Roberto Berlinck & ANJ/Aner \\
\hline $\begin{array}{l}\text { Engenheiro com notório } \\
\text { conhecimento na área de } \\
\text { comunicação social } \\
\text { (inciso IV) }\end{array}$ & Fernando Bittencourt & Miguel Cipolla Jr. & SET \\
\hline $\begin{array}{l}\text { Representante da categoria } \\
\text { profissional dos jornalistas } \\
\text { (inciso V) }\end{array}$ & Daniel Koslowsky Herz & Frederico Barbosa Ghedini & Fenaj \\
\hline $\begin{array}{l}\text { Representante da categoria } \\
\text { profissional dos radialistas } \\
\text { (inciso VI) }\end{array}$ & Francisco Pereira da Silva & $\begin{array}{l}\text { Orlando José Ferreira } \\
\text { Guilhon }\end{array}$ & Fitert \\
\hline $\begin{array}{l}\text { Representante da categoria } \\
\text { profissional dos artistas } \\
\text { (inciso VII) }\end{array}$ & $\begin{array}{l}\text { Berenice Isabel Mendes } \\
\text { Bezerra }\end{array}$ & Stepan Nercessian & Aneate \\
\hline $\begin{array}{l}\text { Representante das } \\
\text { categorias profissionais de } \\
\text { cinema e vídeo (inciso VIII) }\end{array}$ & Geraldo Pereira dos Santos & $\begin{array}{l}\text { Antônio Ferreira de Sousa } \\
\text { Filho }\end{array}$ & STI - Sindcine \\
\hline $\begin{array}{l}\text { Representante da sociedade } \\
\text { civil (inciso IX) }\end{array}$ & $\begin{array}{l}\text { José Paulo Cavalcanti Filho } \\
\text { (jurista com experiência } \\
\text { em questóes de direito } \\
\text { da comunicação eleito } \\
\text { presidente do Conselho) }\end{array}$ & $\begin{array}{l}\text { Manuel Alceu Affonso } \\
\text { Ferreira }\end{array}$ & \\
\hline $\begin{array}{l}\text { Representante da sociedade } \\
\text { civil (inciso IX) }\end{array}$ & Alberto Dines & $\begin{array}{l}\text { Antônio de Pádua Teles de } \\
\text { Carvalho }\end{array}$ & $\mathrm{ABI}$ \\
\hline $\begin{array}{l}\text { Representante da sociedade } \\
\text { civil (inciso IX) }\end{array}$ & Jayme Sirotsky & Jorge da Cunha Lima & $\begin{array}{l}\text { Abert; RBS/Emissoras } \\
\text { Públicas, Educativas e } \\
\text { Culturais }\end{array}$ \\
\hline $\begin{array}{l}\text { Representante da sociedade } \\
\text { civil (inciso IX) }\end{array}$ & Carlos Chagas & Regina Dalva Festa & $\begin{array}{l}\text { Jornais: OESP, O Estado de } \\
\text { Minas, Correio Brasiliense; } \\
\text { Entidades Estaduais de } \\
\text { Rádio e TV/Andi, Jornal } \\
\text { FSP, Seinesp; UOL }\end{array}$ \\
\hline $\begin{array}{l}\text { Representante da sociedade } \\
\text { civil (inciso IX) }\end{array}$ & Ricardo Moretzsohn & $\begin{array}{l}\text { Assunção Hernandes } \\
\text { Moraes de Andrade }\end{array}$ & $\begin{array}{l}\text { CFP Congresso Brasileiro } \\
\text { de Cinema }\end{array}$ \\
\hline
\end{tabular}

Fonte: Relatório de 2002 do Conselho de Comunicação Social. 


\section{Entreato}

Autêntica demonstração de uma "guerra de posiçôes" entre os diversos interesses envolvidos, a instalação do Conselho foi uma vitória para aprimorar as formas de atuação democrática. Mas a "guerra" não foi ganha, ela se dá no dia a dia. Para muitos não há interesse na existência de um Conselho instalado dentro do parlamento capaz de cobrar e debater sobre comunicação, ainda que apenas para consulta e não é casual que desde 2007 o CCS esteja inativo.

Por outro lado, o Fórum Nacional pela Democratização da Comunicação aparece como um novo ator nas discussóes da área das comunicaçóes e fortaleceu, desde então, as entidades que congrega. No entanto, se como principal articulador da lei que instituiu o Conselho reconhece o papel do Estado na formulação da política e da regulamentação da TV a cabo, ao aceitar sua atuação com caráter apenas consultivo - e dessa forma fazê-lo auxiliado pela representação de setores da sociedade civil, suprimindo da composição de seus representantes a participação do Poder Executivo, isto é, do Ministério das Comunicações que havia cumprido funções centralizadoras de coordenação e intervenção -, talvez tenha subtraído a participação de outro ator que poderia fortalecer a ossadura do Conselho. No caso, tratando-se de um momento de transição para um regime democrático, em que a relação se dá com o Poder Legislativo via projetos de lei, não reforçou sua subordinação ao Congresso com a representação das Comissões do Congresso, que poderiam desempenhar o papel de árbitro entre as disputas envolvidas. Assim, a composição do Conselho não pôde se transformar no locus da representação do poder na política das comunicações, assegurando a interlocução entre contrários e estabelecendo uma nova relação entre interesses estatais, públicos e privados.

No entanto, mesmo considerando a transformação de órgão deliberativo em consultivo e o formato diminuto de sua representação, não podemos concordar com as avaliações derrotistas que, analisando os dispositivos da Constituição de 1988 a respeito da regulamentação da indústria da TV no Brasil, os consideraram nulos ou uma falsa vitória das chamadas forças progressistas na Constituinte. Se de fato o
Conselho gerado fosse mera formalidade, pois sem autonomia para punir, certamente sua existência não teria sido postergada por tantos anos.

Para completar, as críticas mencionam que a limitação a oligopólios e monopólios, a finalidade educativa, cultural e informativa dos meios de comunicação, a regionalização e a produção independente e a complementaridade dos sistemas estatal, público e privado não foram satisfatoriamente regulamentadas. Alguns ainda apontaram a fraqueza do Conselho diante da criação da Anatel e, por fim, outros que o Conselho, por não se reunir há mais de um ano, deixou de existir. Na verdade, a Anatel é um órgão regulador das telecomunicações e tem funções administrativas, enquanto ao Conselho cabe um papel eminentemente político, que mesmo com todas as limitações dadas pela falta de sua independência/autonomia, na sua primeira gestão produziu relatórios sobre concentração da propriedade dos meios de comunicação do Brasil, coordenado pelo jornalista Carlos Chagas, e sobre a digitalização.

Sem dúvida, há imprecisões especialmente quanto à falta de critérios claros para a indicação dos representantes dos setores da sociedade civil do CCS, mas também uma atualização no tocante ao restante das vagas, pois não contempla por exemplo os empresários do setor de TV por assinatura, inexistente legalmente quando da aprovação da lei em 1991. No entanto, é preciso haver consenso e participação não apenas de alguns setores mais envolvidos com a área da comunicação, mas de todos aqueles que têm no horizonte um Conselho que possa ser espelho das reais forças das sociedade. Naquele momento, a composição das cinco vagas da sociedade civil, e seus suplentes, como afirmou Herz e Costa, era o resultado de

[...] uma lista com entidades que têm atuado pela democratização da comunicação e que se mobilizaram postulando presença no Conselho (ABI, Abraço, Andi, Congresso Brasileiro de Cinema, Conselho Federal de Psicologia e Enecos) nesta etapa da disputa. No curso dos acontecimentos, surgiu a informação de que havia forte resistência à inclusão de um representante do segmento de radiodifusão comunitária (2002). 
Assim, consultando novamente o quadro dos representantes e as entidades apontadas nesta citação, verificamos que não apenas ficou de fora o representante da Abraço (Radiodifusão Comunitária), como também da Enecos (Executiva Nacional de Estudantes de Comunicação), mas os outros quatro foram eleitos. Ou seja, o processo mostra um resultado positivo para as já históricas entidades envolvidas com a criação do Conselho.

Talvez mais realista seja crer que justamente por ter incomodado em sua primeira gestão, na $2^{\mathrm{a}}$ eleição tenha sido contratado um coveiro, como se referiu Dines (2008a):

Coveiro contratado: o ex-jornalista Arnaldo Niskier. Expert em trabalhos na sombra e em silêncio, o imortal conseguiu o milagre de esvaziar completamente o CCS ao longo do segundo mandato (2005-2006). No ano seguinte (2007), o órgão não se reuniu uma única vez e, em 2008, a Mesa do Senado sequer conseguiu indicar os seus integrantes.

A mesma interpretação pode-se conferir em Costa (2008):

Mesmo com todas as limitações pela falta de independência, seu início contou com uma composição equilibrada e gente disposta a trabalhar. Moretzsohn conta que a experiência foi tão positiva que assustou os empresários e os próprios parlamentares, produzindo relatórios bem fundamentados sobre concentração da propriedade dos meios e, já naquela época, a respeito da digitalização.

Mas a "brincadeira" parou por aí. Veio a segunda gestão, presidida pelo escritor Arnaldo Niskier e apinhada de representantes dos interesses da grande mídia ocupando as vagas da sociedade civil, como previa o senador Pedro Simon. "A segunda gestão teve a sua composição deturpada. Tem que haver um mecanismo para indicação das vagas pelos movimentos sociais", afirma Moretzsohn, do CFP.

E alerta Dines (2008a):

Significa que o CCS é desnecessário?
Significa que o CCS é utilíssimo, não fosse assim não seria sangrado em silêncio. O CCS tem condições para transformar-se num instrumento decisivo para provocar e subsidiar os debates relativos aos meios de comunicação. $\mathrm{O}$ CCS pode ser vital para disciplinar a espúria concessão de canais de rádio e TV a parlamentares, aberração que compromete toda a estrutura da nossa mídia eletrônica.

Embora sem o formato e desprovido dos poderes da FCC americana (Federal Communications Comission), o CCS poderia transformar-se na incubadeira de instrumentos e estatutos - reguladores ou auto-reguladores exigidos por uma sociedade que está aprendendo a comunicar-se em alta velocidade.

Talvez hoje estejamos mais próximos de reformular tanto o caráter como a composição do CCS. O Tribunal de Contas da União (TCU) é um exemplo de que é possível um órgão auxiliar do Legislativo ganhar autonomia posteriormente. Mas, é preciso haver consenso e participação de todos setores envolvidos que possam de fato apresentar propostas democráticas de gerir a comunicação em nossa sociedade.

Quanto ao fato de ele não se reunir e estar ocioso desde o final de 2006, cabe às entidades comprometidas manterem a chama acesa e denunciarem. Não se pode aceitar a paralisação do colegiado, conforme José Paulo Cavalcanti, à falta de entendimento entre as entidades que o compõem: "Os sindicatos parecem atraídos pelo radicalismo, os patrôes querem menos debate e o Congresso quer a reserva de poder" (Cavalcanti apud Damasceno, 2008). Há ainda inúmeras questôes a serem tratadas, algumas mais prosaicas, mas nem por isso menos importantes como a propaganda nas emissoras de TV por assinatura, nos canais infantis, a escrita abreviada nos letreiros de filmes estrangeiros, dublagem etc. Venício Lima, conhecido pesquisador do Núcleo de Estudos sobre Mídia e Política da Universidade de Brasília, chegou a mostrar que a resistência à indicação dos representantes para a instalação do Conselho existe por parte dos senadores, "pois muitos são de- 
Tabela 2

\section{Congresso Nacional/Conselho de Comunicação Social 2a Eleição Geral: Sessão do Congresso Nacional de 16.12.2004}

\begin{tabular}{|c|c|c|}
\hline Lei no 8.389/91, Art. $4^{\circ}$ & Titulares & Suplentes \\
\hline $\begin{array}{l}\text { Representante das empresas de rádio } \\
\text { (inciso I) }\end{array}$ & Paulo Machado de Carvalho Neto & Emanuel Soares Carneiro \\
\hline $\begin{array}{l}\text { Representante das empresas de } \\
\text { televisão (inciso II) }\end{array}$ & Gilberto Carlos Leifert & Antônio de Pádua Teles de Carvalho \\
\hline $\begin{array}{l}\text { Representante de empresas da } \\
\text { imprensa escrita (inciso III) }\end{array}$ & Paulo Tonet Camargo & Sidnei Basile \\
\hline $\begin{array}{l}\text { Engenheiro com notório } \\
\text { conhecimento na área de } \\
\text { comunicação social (inciso IV) }\end{array}$ & Fernando Bittencourt & Roberto Dias Lima Franco \\
\hline $\begin{array}{l}\text { Representante da categoria } \\
\text { profissional dos jornalistas (inciso V) }\end{array}$ & Daniel Koslowsky Herz & Celso Augusto Schöder \\
\hline $\begin{array}{l}\text { Representante da categoria } \\
\text { profissional dos radialistas (inciso VI) }\end{array}$ & Eurípedes Corrêa Conceição & Márcio Leal \\
\hline $\begin{array}{l}\text { Representante da categoria } \\
\text { profissional dos artistas (inciso VII) }\end{array}$ & Berenice Isabel Mendes Bezerra & Stepan Nercessian \\
\hline $\begin{array}{l}\text { Representante das categorias } \\
\text { profissionais de cinema e vídeo } \\
\text { (inciso VIII) }\end{array}$ & Geraldo Pereira dos Santos & Antônio Ferreira de Sousa Filho \\
\hline $\begin{array}{l}\text { Representante da sociedade civil } \\
\text { (inciso IX) }\end{array}$ & Dom Orani João Tempesta & Segisnando Ferreira Alencar \\
\hline $\begin{array}{l}\text { Representante da sociedade civil } \\
\text { (inciso IX) }\end{array}$ & Arnaldo Niskier & Gabriel Priolli Neto \\
\hline $\begin{array}{l}\text { Representante da sociedade civil } \\
\text { (inciso IX) }\end{array}$ & Luiz Flávio Borges D’Urso & Felipe Daou \\
\hline $\begin{array}{l}\text { Representante da sociedade civil } \\
\text { (inciso IX) }\end{array}$ & Roberto Wagner Monteiro & Flávio de Castro Martinez \\
\hline $\begin{array}{l}\text { Representante da sociedade civil } \\
\text { (inciso IX) }\end{array}$ & João Monteiro de Barros Filho & Paulo Marinho \\
\hline
\end{tabular}

Fonte: Disponível em http://www.senado.gov.br/web/comissoes/CCS/Composicao.pdf.

tentores de concessões. [...] Ele não está instalado atualmente porque, mesmo sem poder, pode incomodar" (Lima apud Costa, 2008). Na crise atual, é desconcertante assistir o senador Sarney sob pressões da mídia que ajudou a conservar atuante, desde que fora presidente da República e que, juntamente com o ministro das Comunicaçôes, Antonio Carlos Magalhães, ao conservar Rômulo
Villar Furtado como Secretário Geral desse Ministério no mesmo cargo ocupado durante os três últimos governos militares, manteve o Congresso refém do sistema de concessōes. Sarney, posteriormente presidente do Senado, foi o responsável pela indicação de Niskier ao Conselho de Comunicação Social no mandato 2005-2006, do qual foi eleito presidente. 
Ao final de seu mandato, poderia ter ao menos prorrogado até a posse de seus sucessores, mas Niskier dissolveu o CCS antes de empossar os novos conselheiros. O ex-presidente do Senado, Renan Calheiros, não indicou os substitutos e depois, quando estourou o escândalo que o obrigou a renunciar, sentiu-se desobrigado de fazer as indicaçôes (2008b). Vivenciando a recente crise em torno de seu nome, Sarney talvez cedesse às pressões para empossar um novo Conselho.

Mas, certamente por conta da falta de diálogo, da ausência de um Conselho de Comunicação Social ativo, a fervura tem evoluído e se avoluma com a aproximação da realização da primeira Conferência Nacional de Comunicação Social em dezembro de 2009. Não por conta da grande quantidade de pautas que se acumulam sobre o setor das comunicaçôes no Congresso Nacional e que deveriam ser apreciadas pelo órgão, nem por pressões da Abert ou da Abta que sentem a necessidade diante da pujança com que se dá o avanço das empresas de telecomunicaçōes em um mercado dominado há décadas pelo mesmo oligopólio de radiodifusores, mas certamente para impedir o caos que tempos atrás, como vimos, não chegou a se verificar.

Hoje a ausência de um controle sobre conteúdo dos meios de comunicação, meios percebidos como agentes de novas formas de socialização e com grande influência sobre os indivíduos, é cada vez mais necessária para garantir um controle social que fiscalize e garanta o equilíbrio entre o público e o privado, respeitando os direitos do cidadão.

\section{Notas}

1 O Fórum Nacional pela Democratização da Comunicação foi criado em abril de 1991. Em outubro de 1995, era integrado por 32 entidades nacionais e dezenove Comitês Regionais pela Democratização da Comunicação que aglutinavam 272 entidades regionais.

2 Este item refere-se a uma inovação em relação a outros direitos como saúde, educação e previdência social. Sua inclusão já na Constituinte (art. 223) foi uma forma de equilibrar os já existentes sistema privado e estatal e também equiparar a estes um novo, o sistema público, independente do mercado ou do governo e que foi recentemente utilizado para gerar a TV Brasil.
3 Sobre a introdução da TV por assinatura no Brasil, ver Simis (2005).

4 Como sabemos, mesmo sem a apreciação do Conselho, que só seria instalado anos depois, os atos de regulamentação foram assinados e publicados.

5 Esse prólogo da regulação da TV na Constituinte está ricamente esmiuçado em trabalho posterior de Jambeiro (2001, pp. 148-154). É onde consta que a discordância entre a Frente e a Fenaj referia-se à questão da propriedade dos serviços de rádio e TV: para a primeira as entidades sem fins lucrativos deveriam ter prioridade na concessão dos meios, e não exclusividade, bem como serem isentas de impostos quando explorassem tais meios.

6 Em outro trabalho analiso mais de perto o tema das concessões e considero um avanço a exigência da aprovação do Congresso na questão (Simis, 2006).

7 Cf. Ramos, 2000, pp. 152-153. Infelizmente não tivemos acesso ao projeto de lei 2.120 , de 1991, apresentado à Câmara dos Deputados.

8 O deputado Koyu Iha era o relator do projeto Tilden Santiago.

9 Ofício enviado ao senador Fogaça pelo Coordenador Geral do Fórum em Boletim (1995, p. 15).

10 Sobre a negociação, afirmou Herz e Costa (2002): "Inconformadas com a tendência das oposiçôes votarem a favor da PEC, as entidades do Fórum reivindicaram que as oposições, pelo menos, exigissem a composição do Conselho, antes de viabilizar a votação da PEC.

\section{BIBLIOGRAFIA}

BOLETIM Informativo do Fórum Nacional pela Democratização da Comunicação. (1995), ano 1, n. 1, Brasília, 1 de novembro de 1995, Data*Fórum, arquivo DF-001.

COSTA, Henrique. (2008), "Criação do CCS reflete força dos empresários na Constituinte". Observatório do Direito à Comunicação, 6 out. Disponível em <http://www.direitoacomunicacao.org.br/novo/content.php?option=com._ content\&task=view\&id $=4108>$.

DAMASCENO, Tatiana. (2008), "Parlamentares articulam retomada do Conselho de Comunicação Social. Congresso em Foco". Observatório do Direito à Comunicação, 24 abr. Disponível em <http://www.direitoacomuni- 
cacao.org.br/novo/content.php?option=com content\&task=view\&id=3245>.

DINES, Alberto. (2008a), "Seqüestraram o Conselho de Comunicação Social”. Observatório da Imprensa, 18 mar. Disponível em <http://www. direitoacomunicacao.org.br/novo/content. php?option=com_content $\&$ task=view $\&$ id 2895>.

. (2008b), "Conselho de Comunicação Social: não existe 'buraco negro', está tudo muito claro". Observatório da Imprensa, 1 abr.

HERZ, Daniel \& COSTA, Beth. (2002), "10 anos depois, nasce Conselho de Comunicação Social”. Brasília, 22 de maio de 2002. Disponível em <http://www.fndc.com.br/data/Historia_ Conselho.doc>.

JAMBEIRO, Othon. (2000), Regulando a TV: uma visão comparativa no Mercosul. Salvador, EDUFBA.

(2001), A TV no Brasil do século XX. Salvador, Edufba.

NOGUEIRA, Aguinaldo. (1996), "Em poucas semanas, saem os editais de TV a cabo e MMDS". Revista Pay TV, 18, jan.

O ESTADO DE S. PAULO. (1995), "Motta propõe mudança na concessão de canais". O Estado de S. Paulo, 31 ago.

RAMOS, Murilo César. (2000), "A TV por assinatura no Brasil: conceito, origens, análise e perspectivas, in Às margens da estrada do futuro: comunicaçôes, política e tecnologia. Brasília, Coleção FAC Editorial Eletrônica, cap. 7. Disponível em <http://www2.eptic.com.br/ sgw/data/bib/livros/d18086a2e91f17dfa9214a977c047054.pdf>.

RELATÓRIO de 2002 do Conselho de Comunicação Social. Disponível em <http://webthes.senado. gov.br/bin/gate.exe?f=tocn \&p_toc=tocn $\&$ p_ doc $=$ recordn $\&$ p_d=SILN\&p_op_all=E\&p_ SortBy $1=$ DINV \&p_Ascend $1=$ no $\&$ p_ SortBy $2=S$ ASS \& p_Ascend $2=$ no $\&$ p lang $=$ english \&expr $=$ ALL\&p_s_ALL $=\% 40 D$ $\mathrm{OCN}+\mathrm{E}+\mathrm{COPARL}[\mathrm{NV01}]+\mathrm{E}+\mathrm{CCS}[\mathrm{NV} 02]$ $+\mathrm{E}+$ Historico[NV03] \&p_search $=$ search \&a_ search=ENTRA\&p_L=10\#>.

SIMIS, A. (2005), "Introdução da TV por assinatura no Brasil: algumas questōes", in Othon
Jambeiro, Valério Brittos e Álvaro Benevenuto Jr. (orgs.), Comunicação, hegemonia e contrahegemonia. Salvador, EDUFBA, pp. 115-130. (2006), "A legislação sobre as concessões na radiodifusão". Unirevista, 1 (3), jul. Disponível em <http://www.alaic.net/ponencias/UNIrev_Simis.pdf\#search=\%22anita\%20 simis\%22>.

FOLHA DE S. PAULO. (2002), "Sociedade servidora". Folha de S. Paulo, 18 maio. . (2002), "Votação sobre capital externo pode ser adiada". Folha de S. Paulo, 21 maio. 


\section{CONSELHO DE COMUNICAÇÃO SOCIAL: UMA VÁLVULA PARA O DIÁLOGO OU PARA O SILÊNCIO?}

\section{Anita Simis}

Palavras-chave: Conselho de Comunicação Social; Democratização da comunicação; Representação dos meios de comunicação.

Este trabalho analisa o Conselho de Comunicação Social, sua importância e sua trajetória, procurando explicar por que tal Conselho,regulamentado em 1991, só foi efetivamente implantado 14 anos depois. Após um curto período de funcionamento, não houve a renovação da gestão e, desde dezembro de 2006 , ele está ocioso. No entanto, a necessidade de funcionamento do Conselho é apontada por diversos setores, ainda que com mudanças em seu caráter e representação.
COUNCIL OF SOCIAL COMMUNICATION: A VALVE TOWARD DIALOGUE OR TOWARD SILENCE?

\section{Anita Simis}

Keywords: Council of Social Communication; Democratization of the communication; Representation of the communication media.

This work analyzes the Council of Social Communication, its importance and its trajectory, trying to explain why the Council ruled in 1991, was implanted only 14 years later. After a short period of functioning, there was not a renewal of the management and, since December 2002, it has been idle. Nevertheless, the necessity of the Council management is pointed out by various sectors, though with changes in its character and representation.
CONSEIL DE COMMUNICATION

SOCIALE: UNE ALTERNATIVE POUR LE DIALOGUE OU POUR LE SILENCE ?

\section{Anita Simis}

Mots-clés : Conseil de Communication Sociale; Démocratisation de la communication; Représentation des moyens de communication.

Le présent travail propose une analyse du Conseil de Communication Sociale, de son importance et de sa trajectoire. Il tente d'expliquer la raison par laquelle ce Conseil, réglementé en 1991, n’a été effectivement mis en place que 14 ans plus tard. Suite à une brève période de fonctionnement, il n'y a pas eu de renouvellement de sa gestion et, depuis décembre 2002, il demeure oisif. Cependant, le besoin de fonctionnement du Conseil est signalé par plusieurs secteurs, même si accompagné de demandes de changements para rapport à son caractère et à sa représentation. 